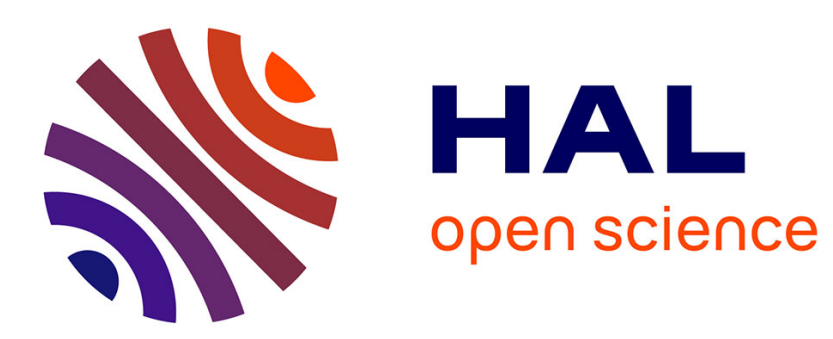

\title{
Role of machining defects and residual stress on the AISI 304 fatigue crack nucleation
}

H Yahyaoui, N Ben Moussa, Chedly Braham, H Sidhom

\section{To cite this version:}

H Yahyaoui, N Ben Moussa, Chedly Braham, H Sidhom. Role of machining defects and residual stress on the AISI 304 fatigue crack nucleation. Fatigue and Fracture of Engineering Materials and Structures, 2015, 38, pp.420-433. 10.1111/ffe.12243 . hal-01192691

\section{HAL Id: hal-01192691 \\ https://hal.science/hal-01192691}

Submitted on 3 Sep 2015

HAL is a multi-disciplinary open access archive for the deposit and dissemination of scientific research documents, whether they are published or not. The documents may come from teaching and research institutions in France or abroad, or from public or private research centers.
L'archive ouverte pluridisciplinaire $\mathbf{H A L}$, est destinée au dépôt et à la diffusion de documents scientifiques de niveau recherche, publiés ou non, émanant des établissements d'enseignement et de recherche français ou étrangers, des laboratoires publics ou privés. 


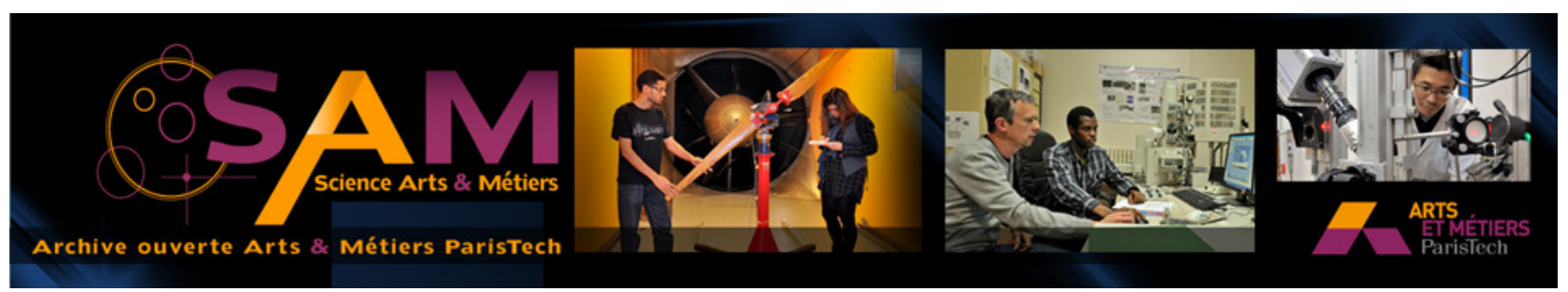

Science Arts \& Métiers (SAM)

is an open access repository that collects the work of Arts et Métiers ParisTech researchers and makes it freely available over the web where possible.

This is an author-deposited version published in: http://sam.ensam.eu

Handle ID: .http://hdl.handle.net/10985/9901

\section{To cite this version :}

H YAHYAOUI, N BEN MOUSSA, Chedly BRAHAM, H SIDHOM, N BEN FREDJ - Role of machining defects and residual stress on the AISI 304 fatigue crack nucleation - Fatigue and Fracture of Engineering Materials and Structures - Vol. 38, p.420-433 - 2015 


\title{
Role of machining defects and residual stress on the AISI 304 fatigue crack nucleation
}

\author{
H. YAHYAOUI ${ }^{1}$, N. BEN MOUSSA ${ }^{1}$, C. BRAHAM ${ }^{2}$, N. BEN FREDJ ${ }^{1}$ and H. SIDHOM ${ }^{1}$ \\ ${ }^{1}$ Mechanical, Materials, and Processes Laboratory, University of Tunis, (LR99ES05), ESSTT, 5, Avenue Taha Hussein, 1008, Tunisia, ${ }^{2}$ Laboratoire \\ Procédés et Ingénierie en Mécanique et Matériaux (CNRS UMR 8006), Arts et Métiers-ParisTech, 151 Bd de l'Hôpital, 75013 Paris, France
}

\begin{abstract}
A B S TRACT Machining defects as rebuilt material and dislodgement were often induced by cutting of difficult to machining AISI 304 stainless steel. Their density increases with a decreasing of cutting speed. The effect of these defects on surface topography and residual stress was evaluated by roughness and X-ray diffraction measurements coupled with numerical simulation. The role of the rebuilt material on the distribution of fatigue crack nucleation sites was investigated by scanning electron microscope examination of post fatigue samples loaded at different imposed strain amplitudes. The association of machining defects and fatigue crack nucleation sites was attributed to the contribution of additional tensile residual stresses induced by rebuilt material rather than local stress concentration. Moreover, the fatigue crack coalescence is promoted by increasing the rebuilt material density. When the machining defect density increases from 5 to 60 particles $/ \mathrm{mm}^{2}$, the fatigue life decreases from $-22 \%$ to $-65 \%$ with respect to the electropolished surface.
\end{abstract}

Keywords stainless steel; machining defects; residual stress; fatigue life; crack distribution.

NOMENCLATURE

$a p=$ depth of cut

$f=$ feed rate $(\mathrm{mm} / \mathrm{rev})$

$F_{\mathrm{c}}=$ cutting force $(\mathrm{N})$

$F_{f}=$ feed force $(\mathrm{N})$

$F_{f r}=$ frictional force $(\mathrm{N})$

$H=$ workpiece height $(\mathrm{mm})$

$b=$ air convection factor $W / \mathrm{m}^{2}{ }^{\circ} \mathrm{C}$

$K_{\text {eff }}=$ high effective stress intensity

$K_{\mathrm{S}}=$ stress intensity due to external loading

$K_{\mathrm{RES}}=$ stress intensity due to the tensile residual stress

$K_{t}=$ stress concentration factor

$N_{\mathrm{R}}=$ number of strain cycles to failure

$Q_{f}=$ rate of heat generation at the shear plane heat source $(\mathrm{W})$

$Q_{r}=$ rate of heat generation at the rake face heat source $(W)$

$R=$ workpiece radius $(\mathrm{mm})$

$R_{\varepsilon}=$ strain ratio

$R_{a}=$ arithmetic roughness parameters $(\mu \mathrm{m})$

$R_{t}=$ total roughness parameters $(\mu \mathrm{m})$

$r_{c}=$ rebuilt material radius $(\mu \mathrm{m})$

$r_{\varepsilon}=$ tool nose radius $(\mathrm{mm})$

$T_{0}=$ initial workpiece temperature $\left(20^{\circ} \mathrm{C}\right)$

$\mathrm{Tm}=$ melting temperature

A B n m = Johnson Cook parameters

$V_{c}=$ cutting speed $(\mathrm{m} / \mathrm{min})$

$d a / d N=$ crack propagation rate

Correspondence: H. Sidhom. E-mail: habib.sidhom@gmail.com 


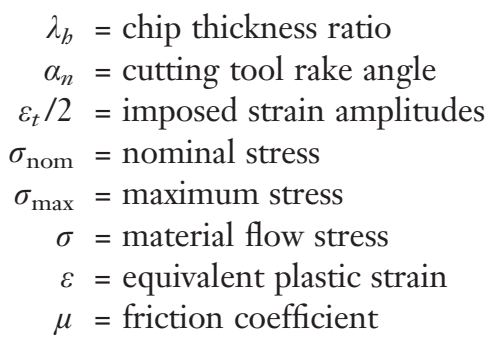

\section{INTRODUCTION}

Austenitic stainless steels, with moderate mechanical characteristic, have important applications when high corrosion resistance is required. They are usually used in manufacturing of chemical components, cryogenic vessels and food equipments. Most of them are manufactured by machining process such as turning or milling and some of them finished by grinding in despite of their difficult machinability compared with carbon and low alloy steels. ${ }^{1}$ These difficulties are related by several authors $^{2,3}$ to their high work-hardening rate, high builtup edge tendency, high ductility, and low thermal conductivity, which are considered by Xavior et al. ${ }^{4}$ as responsible for the poor surface finish and high tool wear. Indeed, the tendency of highly ductile austenitic stainless steels to form a large and unstable built-up edge (BUE) deteriorates the surface quality. ${ }^{2}$ The mechanism of degradation of the surface quality by the built-up edge was provided by Selvam et al.. ${ }^{5}$ They reported that the built-up edge grows in size during machining and digging into the workpiece. Moreover, when built-up edge reaches a critical size, its outer layer breaks and welds on the machined surface leading to deterioration of micro-geometrical quality. The consequence of BUE on the roughness increasing was assessed by Cifti et al. and Bakkal et al. ${ }^{2,6}$ for both materials AISI 316 and AISI 304. Selvam et al. ${ }^{5}$ reported that roughness profiles of plain carbon steel are characterized by a saw-tooth form resulting from the welded BUE on the machined surface. Furthermore, they concluded that, when the built-up edge is present, the cutting edge of the tool is separated from the machined surface and metal is removed by ploughing rather than shearing. This ploughing action leaves a severely strain-hardened layer on the machined surface. On the other hand, Arunachalam et al. ${ }^{7}$ showed high tensile residual stress values, which are mostly attributed to the localized thermal effect due to deposition of residual built-up edge to the machined surface. These surface defects are expected to deteriorate the surface integrity under loading conditions by their effect on the fatigue crack nucleation and growth. Few literature data are related to the quantitative assessment of surface defects and topography on the fatigue life of machined components. ${ }^{8}$ Results presented by Lee et al. ${ }^{9}$ are only limited to the effect of surface roughness on low-cycle fatigue behavior and crack initiation of the AISI 304. Authors concluded that the number of cycles to crack initiation decreases with an increase in surface roughness. Indeed, surface grooves act as crack initiation sites. However, for an electropolished specimen, it was observed that crack initiates at grain boundaries due to strain incompatibility between adjoining grains.

In this paper, the effects of the machined surface properties and particularly the rebuilt material and surface topography on the fatigue crack network characteristics are investigated experimentally and numerically. To evaluate the effect of machining defects on the fatigue life time, experimental investigation is conducted on three AISI 304 machined surfaces with various defect densities resulting from different cutting parameters. Numerical approach is developed to quantify the contribution of the rebuilt material on the residual stress distribution, which controls the fatigue live of machined parts.

\section{MATERIAL AND CUTTING CONDITIONS}

\section{MATERIAL}

The chemical composition, the tensile properties, hardness, and toughness of the AISI 304 austenitic stainless steel are given in Table 1. The annealed structure is shown in Fig. 1.

\section{Cutting conditions}

Fatigue test specimens with a diameter of $10 \mathrm{~mm}$ were prepared by turning (Fig. 2). The cutting conditions, given in Table 2 (Columns A, B, C, and D), were selected for obtaining the formation of different rates of both material build up and dislodgement. ${ }^{3,6,10}$ The used inserts are VBMT 160404-MF as referenced by Sandvik ISO designation. The insert geometry is characterized by nose radius $r_{\varepsilon}=0.4 \mathrm{~mm}$ and tool rake angle $\alpha_{n}=0^{\circ}$. 
Table 1 Chemical composition and thermo-mechanical characteristics of AISI 304 (weight \%)

\begin{tabular}{|c|c|c|c|c|c|c|c|}
\hline $\mathrm{C}$ & $\mathrm{Si}$ & $\mathrm{Cr}$ & Mn & $\mathrm{Ni}$ & Mo & $\mathrm{Cu}$ & $\mathrm{Fe}$ \\
\hline \multirow{8}{*}{$\begin{array}{l}0.05 \\
\text { Young } \\
\text { modulus } \\
\mathrm{E}(\mathrm{GPa}) \\
193\end{array}$} & 0.41 & 18.04 & 1.14 & 9.05 & 0.19 & 0.35 & Balance \\
\hline & & Yield stress & Ultimate tensile & Elongation \% & Hardness & Toughness & Thermal \\
\hline & & $R_{e}(\mathrm{MPa})$ & strength $R_{m}(\mathrm{MPa})$ & & $H_{v}(100 \mathrm{gf})$ & $\operatorname{Kcv}\left(\mathrm{J} / \mathrm{cm}^{2}\right)$ & conductivity \\
\hline & & & & & & & $\mathrm{W} / \mathrm{m} \mathrm{K}$ \\
\hline & & 260 & 670 & 53 & 172 & 270 & $\begin{array}{l}14.6\left(T=20^{\circ} \mathrm{C}\right) \\
28.5\left(T=1000^{\circ} \mathrm{C}\right)\end{array}$ \\
\hline & \multicolumn{7}{|c|}{ Johnson Cook parameters } \\
\hline & & $\mathrm{A}(\mathrm{MPa})$ & $\mathrm{B}(\mathrm{MPa})$ & $\mathrm{n}$ & $\mathrm{m}$ & & \\
\hline & & 320 & 1200 & 0.7 & 1 & & \\
\hline
\end{tabular}

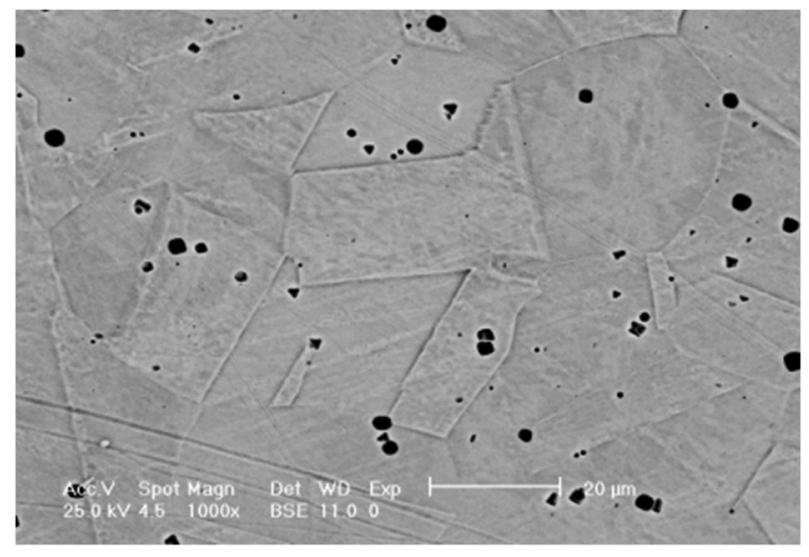

Fig. 1 Austenitic structure of the AISI 304 (grain size around $50 \mu \mathrm{m}$ ).

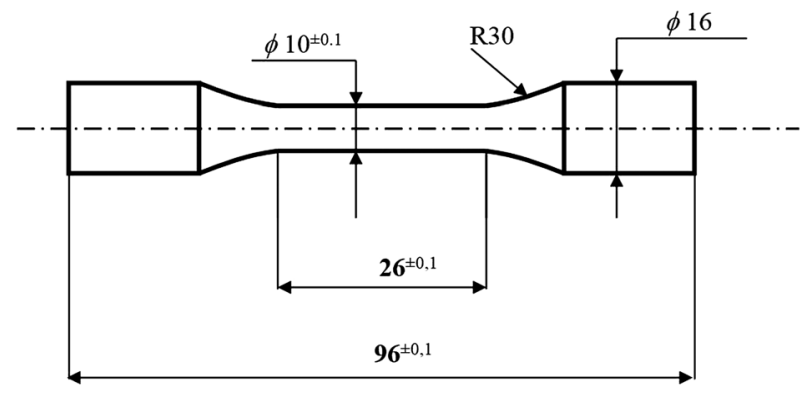

Fig. 2 Geometry of fatigue test specimens (all dimensions are in $\mathrm{mm}$ ).

\section{Experimental setup}

The three components of the cutting forces were measured using a transducer-type dynamometer Kistler type
9255B. Scanning electron microscope (SEM) examinations were performed to investigate the cutting surface defects. The surface roughness was measured using a MITUTOYO Surftest type SJ.301. The hardness of both surface and subsurface was evaluated using a Shimadzu HMV2000 micro-hardness device.

Machining-induced residual stress profiles were obtained by X-ray diffraction measurement using a SET$\mathrm{X}$ diffractometer under the conditions listed in Table 3.

Compression-tensile fatigue tests were carried out at different imposed strain amplitudes $\left(\Delta \varepsilon_{t} / 2=0.3,0.5 \%\right.$, and $1 \%$ ) using an MTS 813 type fatigue testing machine. Strains were measured by a $25 \mathrm{~mm}$ gage length extensometer (model 632.11 F-20, MTS). The selected strain ratio and frequency were $R_{\varepsilon}=-1$ and $0.1 \mathrm{~Hz}$, respectively. All fatigue tests were conducted until specimen rupture. SEM examinations were performed to identify sites of the fatigue crack nucleation.

\section{RESULTS}

\section{Evaluation of the tool-material friction}

The tool-material friction characterized by the Coulomb coefficient $\mu$ was evaluated through the measurement of the cutting force components according to Eq. (1). ${ }^{11}$

$$
\mu=\frac{F_{c} \tan \alpha_{n}+F_{f}}{F_{c}-F_{f} \tan \alpha_{n}}
$$

Table 2 Selected turning conditions, cutting forces, feed forces and friction coefficients

\begin{tabular}{lcccccccc}
\hline $\mathrm{A}$ & $\mathrm{B}$ & $\mathrm{C}$ & $\mathrm{D}$ & $\mathrm{E}$ & $\mathrm{F}$ & $\mathrm{G}$ & $\mathrm{H}$ & $\mathrm{I}$ \\
\hline $\begin{array}{l}\text { Cutting } \\
\text { condition }\end{array}$ & $\begin{array}{c}\text { Cutting speed } \\
V_{c}(\mathrm{~m} / \mathrm{min})\end{array}$ & $\begin{array}{c}\text { Feed rate } \\
f(\mathrm{~mm} / \mathrm{rev})\end{array}$ & $\begin{array}{c}\text { Depth of } \\
\text { cut } a_{p}(\mathrm{~mm})\end{array}$ & Cooling & $\begin{array}{c}\text { Cutting force } \\
F_{c}(\mathrm{~N})\end{array}$ & $\begin{array}{c}\text { Feed force } \\
F_{f}(\mathrm{~N})\end{array}$ & $\begin{array}{c}\text { Friction } \\
\text { coefficient } \mu\end{array}$ & Ref. \\
\hline $\mathbf{1}$ & 45 & 0.05 & 0.2 & Dry & 120 & 100 & 0.83 & {$[6]$} \\
$\mathbf{2}$ & 200 & 0.125 & 2 & Dry & 1800 & 1300 & 0.72 & {$[10]$} \\
$\mathbf{3}$ & 165 & 0.2 & 2.5 & Dry & 1800 & 1000 & 0.55 & {$[3]$} \\
\hline
\end{tabular}


Table 3 X-ray diffraction parameters

\begin{tabular}{|c|c|c|c|c|c|}
\hline \multirow[b]{2}{*}{ Radiation } & $\operatorname{Cr} K \alpha$ & & & & \\
\hline & $\lambda=0.22911 \mathrm{~nm}$ & & & & \\
\hline Voltage & $20 \mathrm{kV}$ & & & & \\
\hline Current & $5 \mathrm{~mA}$ & & & & \\
\hline X-ray diffraction planes & $\left\{\begin{array}{lll}2 & 1 & 1\end{array}\right\}$ & $2 \theta=152^{\circ}$ & & & \\
\hline$\phi$ angles & $0^{\circ}$ & & & & \\
\hline$\psi$ angles & $39.23^{\circ}$ & $35.84^{\circ}$ & $32.31^{\circ}$ & $28.56^{\circ}$ & $24.46^{\circ}$ \\
\hline & $19.76^{\circ}$ & $13.83^{\circ}$ & $0.0^{\circ}$ & $-9.73^{\circ}$ & $-17.02^{\circ}$ \\
\hline & $-22.21^{\circ}$ & $-26.57^{\circ}$ & $-30.47^{\circ}$ & $-34.10^{\circ}$ & $-37.55^{\circ}$ \\
\hline
\end{tabular}

where $F_{c}$ is the cutting force (circumferential direction), $F_{f}$ is the feed force (longitudinal direction), and $\alpha_{n}$ is the cutting tool rake angle.

The values of the measured cutting forces, perfectly constant during machining as shown in Fig. 3, are given in Table 2 (Columns F and G). Consequently, these values are used to calculate friction coefficients considered constants and given in Table 2 (Columns H). It should be noted that the calculated friction coefficients for cutting Conditions 1 and 2 are much higher than Condition 3.

\section{Machined surface characterization Surface defects}

Scanning electron microscope examinations of machined surfaces reveal material rebuilt and dislodgement having densities and dimensions that mainly depend on the cutting conditions, as it can be seen in Table 4. It should be noted that the high density of rebuilt material is found when the cutting speed is low (Condition 1).

\section{Surface work-hardening}

The micro-hardness profiles (Fig. 4) show the existence of work-hardened layers induced by plastic deformation during machining for all cutting conditions. However, machining under Conditions 1 and 2 induces higher hardening at the outer layers than in Condition 3.

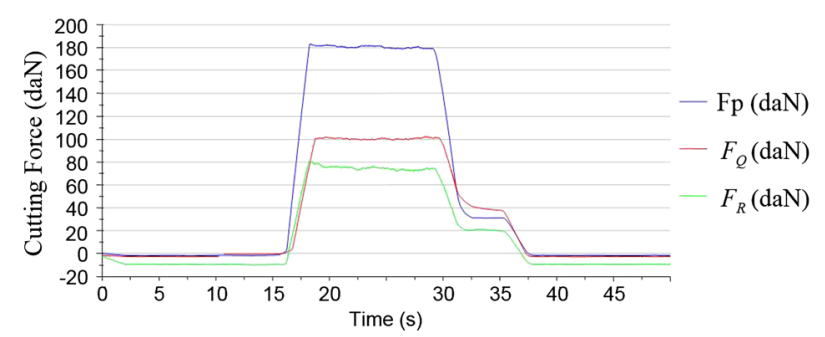

Fig. 3 Cutting forces measured during machining of the AISI 304 in the Condition 3.

\section{Surface roughness}

The arithmetic $\left(R_{a}\right)$ and the total $\left(R_{t}\right)$ roughness parameters give a general appreciation of the machined surface topography. These values seem to decrease unexpectedly with a decrease in the feed speed when the geometrical model of these parameters is considered. This unexpected tendency is explained by the analysis of the roughness profiles given in Table 5. Indeed, the surface roughness profiles are very informative concerning the existence of the aforementioned surface defects that contribute significantly in increasing the values of the roughness parameters. Therefore, roughness values corresponding to cutting Condition 1, characterized by high densities of material rebuilt and dislodgement, are higher than those corresponding to Conditions 2 and 3 . The roughness profiles of Conditions 2 and 3 are much more regular.

\section{Stress micro-concentration sites}

The stress concentration factor at the bottom of the cutting grooves $\left(k_{t}=\frac{\sigma_{\max }}{\sigma_{\operatorname{nam}}}\right)$ was calculated by the finite element model using ABAQUS software, where $\sigma_{\text {nom }}$ is the nominal stress, and $\sigma_{\max }$ is the maximum stress. The topography of turned surface is quite regular as evidenced by experimental roughness profiles shown in Table 5. In the numerical procedure, the notches described by the roughness profiles are faithfully reproduced on the surface of a cylindrical specimen loaded under tensile condition in order to estimate the local stress concentration factor resulting from machining grooves (Fig. 5). An elastic stress calculation provides the values of the micro-concentration factor $\left(K_{t}\right)$ that are given in Table 5 .

\section{Machined surface residual stress distribution}

In this investigation, two orders of residual stresses are considered:

- The macro residual stresses were experimentally measured. The origins of these stresses are the thermal and mechanical effects that occur from material-tool interactions during the cutting process. 


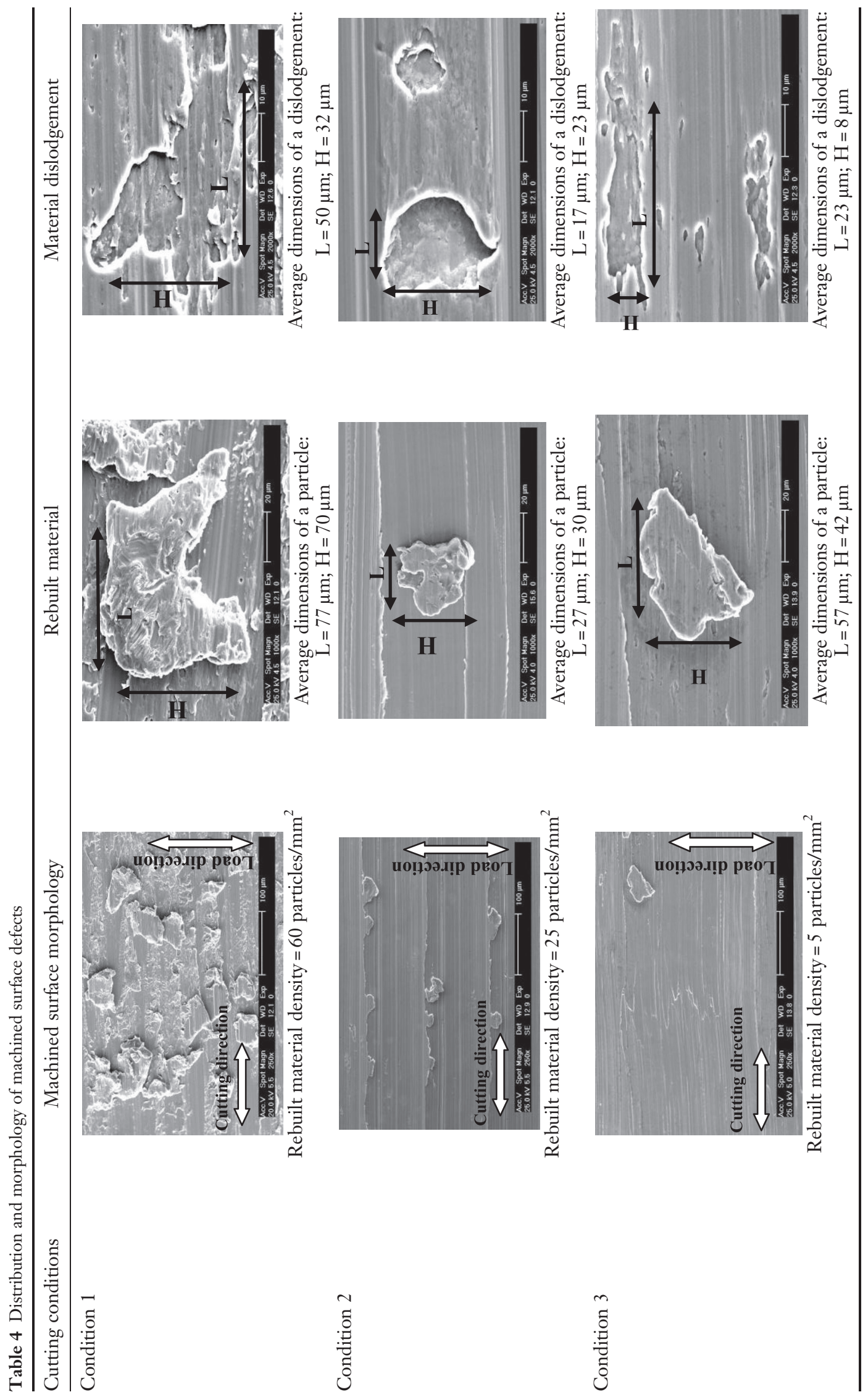




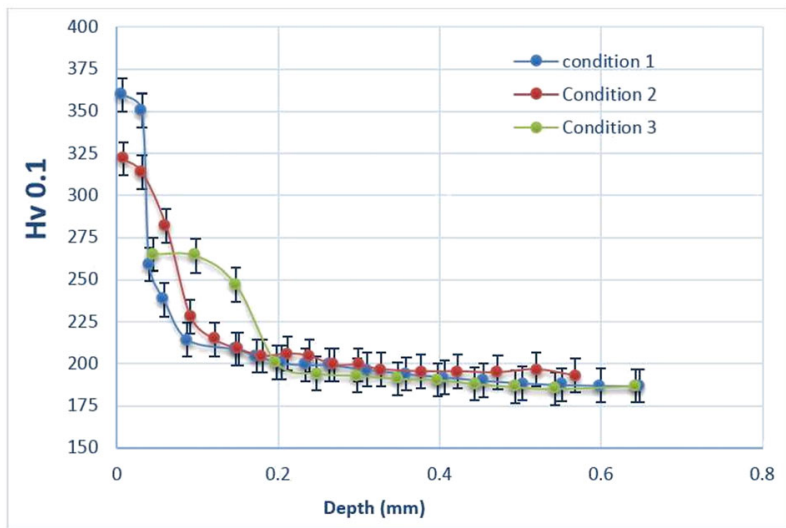

Fig. 4 Micro-hardness profiles of the turned surfaces of the AISI 304 stainless steel.

- The local residual stresses were numerically calculated. The origins of these stresses are the thermal contribution of the rebuilt material that provides an additional local heat flux and modifies the friction coefficient.

\section{Residual stress distribution: experimental measurements}

The measured residual stress profiles are in good agreement with the cutting conditions severity (Fig. 6). Indeed, the near surface hoop tensile residual stress levels increase with an increase in the cutting speed $\left(V_{c}\right)$. However, the axial residual stresses are compressive for all cutting conditions.

\section{Local residual stress distribution: numerical simulation}

The role of the rebuilt material is tribologically equivalent to a third compound in a dynamic tribological system composed of the couple cutting tool and cut material. Under this hypothesis, the friction coefficient $(\mu)$ and heat dissipated energy at the interface toolmaterial are locally modified. Therefore, the local tensile residual stresses are expected to reach high values comparatively with a state that is exempt from rebuilt material. At this scale, the experimental assessment of the residual stresses is not accessible using a conventional $\mathrm{X}$-ray diffraction setup. For this reason, an attempt is made, in this paper, to evaluate these stresses using a numerical approach by means of ABAQUS software. The validation of the numerical results is made according to two models:

- First model: the macro residual stresses are calculated without considering the effects of the rebuilt material and compared to experimental measurements. The validation of the numerical approach is made at this step.

- Second model: both effects of the rebuilt material as an additional heat source and as a local friction law modification are considered. The methodology used to predict residual stress is presented in Fig. 7.

\section{Modeling}

The heat generated during machining by tool-material friction and plastic deformation is considered as the main origin of the temperature increase at the cutting zone $^{12}$ :

- The heat generated by friction at the cutting toolmaterial interface is divided into three fractions: $75 \%$ of the heat is evacuated by the chips, $20 \%$ is dissipated into the workpiece material and the cutting tool receive $4-5 \% .{ }^{13}$ Therefore, the frictional heat is calculated from the friction energy given by the following equation $^{14}$ :

$$
Q_{f}=\frac{F_{f r} V_{c}}{\lambda_{b}}
$$

where $F_{f r}$ is the frictional force, $V_{c}$ is the cutting speed, and $\lambda_{\mathrm{h}}$ is the chip thickness ratio (the thickness of the chip prior to chip formation divided by the chip thickness after separation).

- The heat generated by plastic strain can be determined using the following hypothesis: $90 \%$ of the plastic energy is converted to heat. ${ }^{15}$ In addition, $60-70 \%$ of this heat is evacuated by the chips, and $30-40 \%$ is dissipated into the workpiece material. ${ }^{16}$ The heat generation in the primary deformation zone may be calculated from the work performed and the cutting force $F_{c}$, as ${ }^{14}$ :

$$
Q r=F_{c} V_{c}
$$

where $F_{c}$ is the cutting force, and $V_{c}$ is the cutting speed.

\section{Material behavior}

The constitutive law proposed by Johnson and $\mathrm{Cook}^{17}$ and described by Eq. (4), is used to describe the AISI 314 stainless steel behavior.

$$
\sigma=\left(A+B(\varepsilon)^{n}\right)\left(1-\left(\frac{T-T_{0}}{T_{m}-T_{0}}\right)^{m}\right)
$$

In Eq. (4), $\sigma$ is the material flow stress, $\varepsilon$ is the equivalent plastic strain, $T_{0}$ and $T_{m}$ are the room and melting temperatures equal to 20 and $1450{ }^{\circ} \mathrm{C}$, respectively. The coefficients (A, B, n, and $\mathrm{m}$ ), listed in Table 1 , are obtained from tensile curves corresponding to different temperatures using a least squares fit method. 


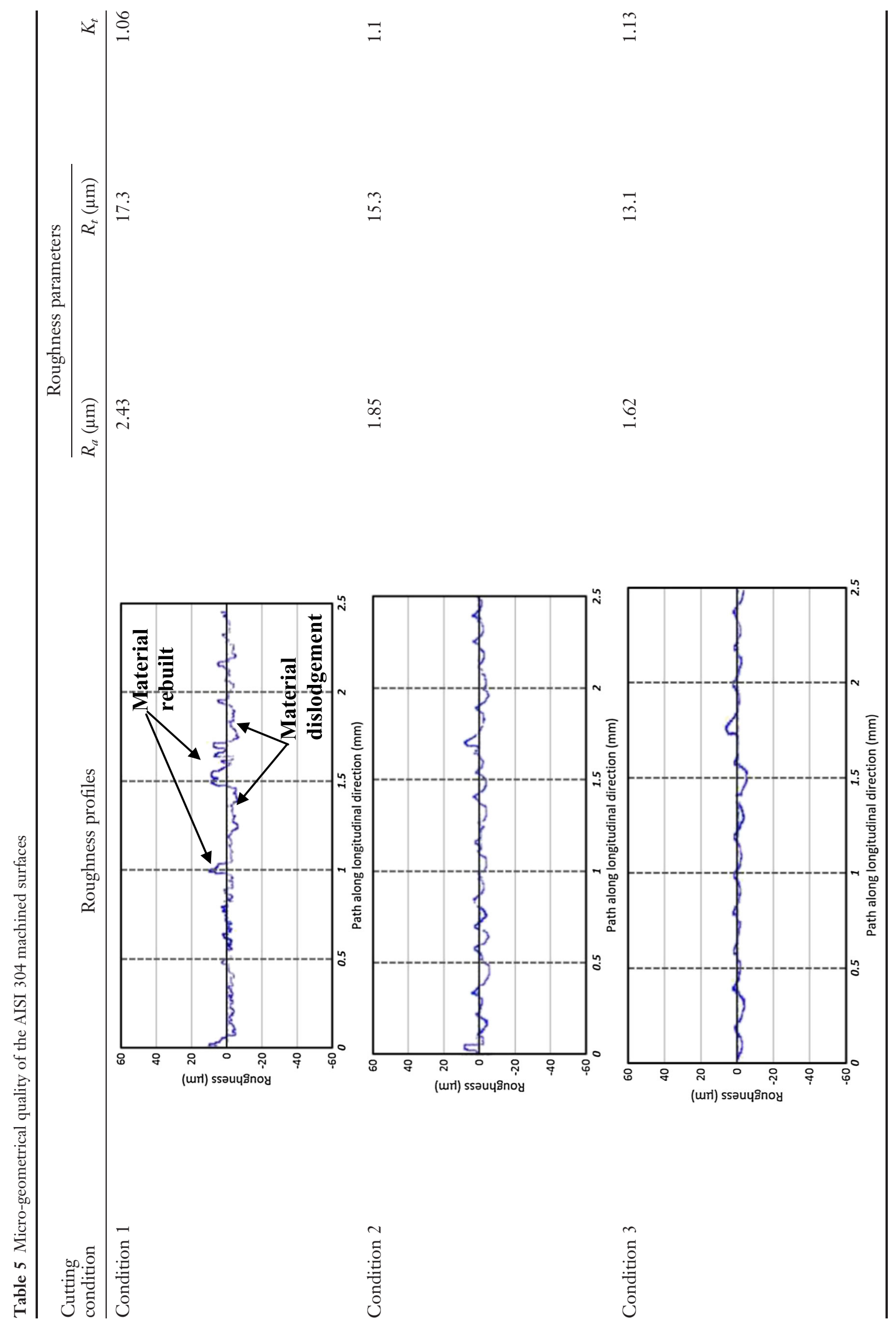



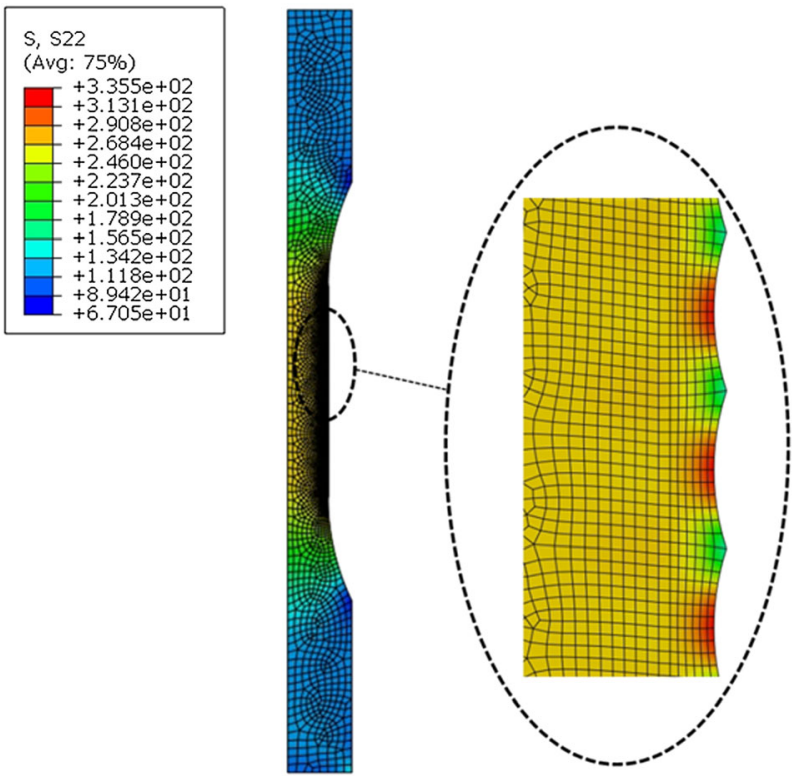

Fig. 5 Numerical simulation of machined surface topography and stress micro-concentration factor calculation.

\section{Geometry, mesh, and boundary conditions}

The workpiece geometry as well as initial and boundary conditions are introduced into the model (Fig. 8). The workpiece geometry is introduced with a radius $R=5 \mathrm{~mm}$ and a height $H=13 \mathrm{~mm}$ and taking into account in axi-symmetry. These dimensions are supposed to be infinite comparatively with the average size of the rebuilt material $\left(r_{c}=25,15\right.$, and $10 \mu \mathrm{m}$ for cutting Conditions 1 , 2 , and 3 , respectively). Therefore, a specific heat flux is applied to the zone corresponding to rebuilt material average size. The workpiece is meshed using 2277 elements type CAX4T. The mesh is extremely refined near the zone where the heat flux is applied (Fig. 8). The two steps (heating and cooling) of residual stress generation operate simultaneously during machining. Then, the room temperature is totally reached before stopping the workpiece rotation. Thus, a factor value corresponding to a forced air convection $b=48,41 \mathrm{~W} /\left(\mathrm{m}^{2} .{ }^{\circ} \mathrm{C}\right)$, adopted in previous work, ${ }^{18}$ is used to control the heat transfer between the part and the ambient air.

\section{Simulation results and validation}

Using the previously described model, the nodal temperature distributions corresponding to cutting Condition 1 is calculated and plotted in Fig. 9. The numerical results show that the temperature rises when the additional heat flux describing the rebuilt material is taken into account in the simulation.

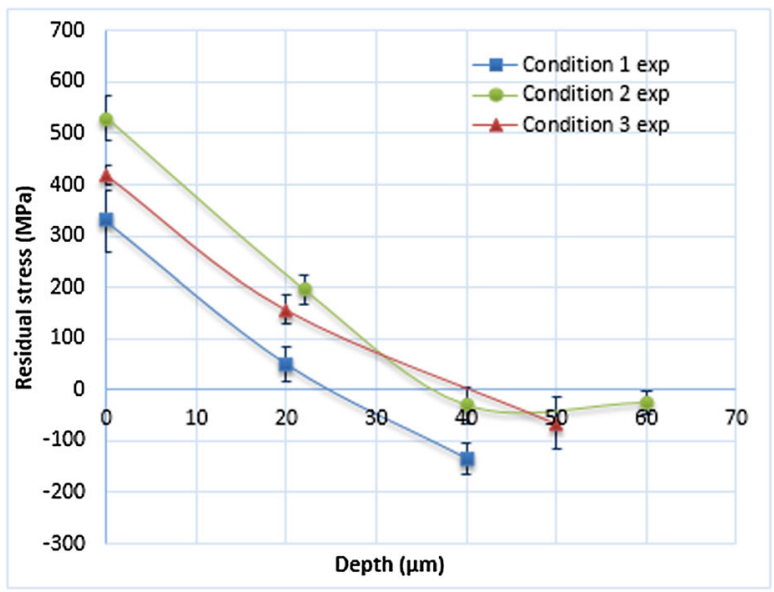

(a)

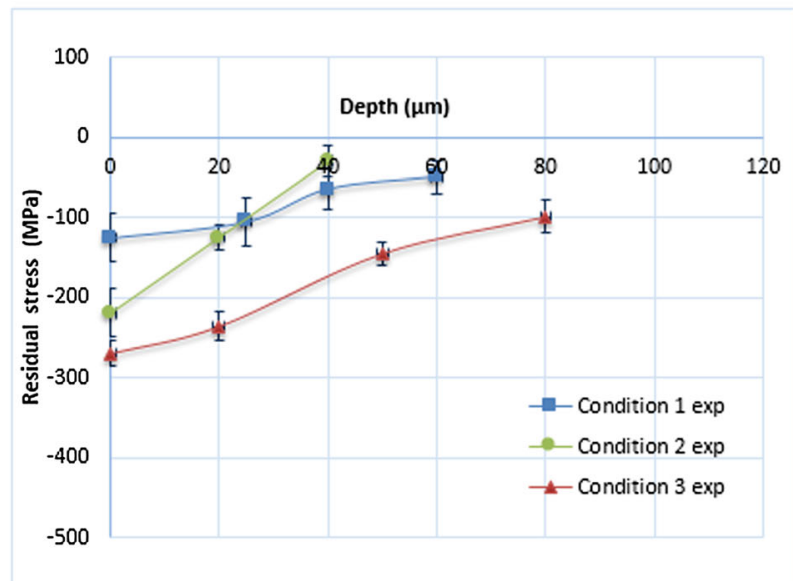

(b)

Fig. 6 Effect of cutting conditions on the residual stress: (a) hoop stress and (b) axial stress.

For the case where the thermal effects of the rebuilt material are not considered, it can be stated that the simulated profiles of the residual stress distributions agree with the measured ones, with some scattering attributed to the material big grain size, for all cutting conditions and both measurement directions (Fig. 10a and b). Nevertheless, for the case where the additional thermal effect and friction coefficient modification are introduced to account for the rebuilt material effect, the residual stress levels increase significantly (Fig. 10c and d).

\section{Effects of the cutting surface defects on the fatigue strength Fatigue life time}

Low-cycle fatigue life of AISI 304 machined parts are compared to the electropolished state exempt of defect and considered as the reference state in this work. Table 6 reveals a reduction of the fatigue life of machined parts comparatively with the reference state (values are the average 


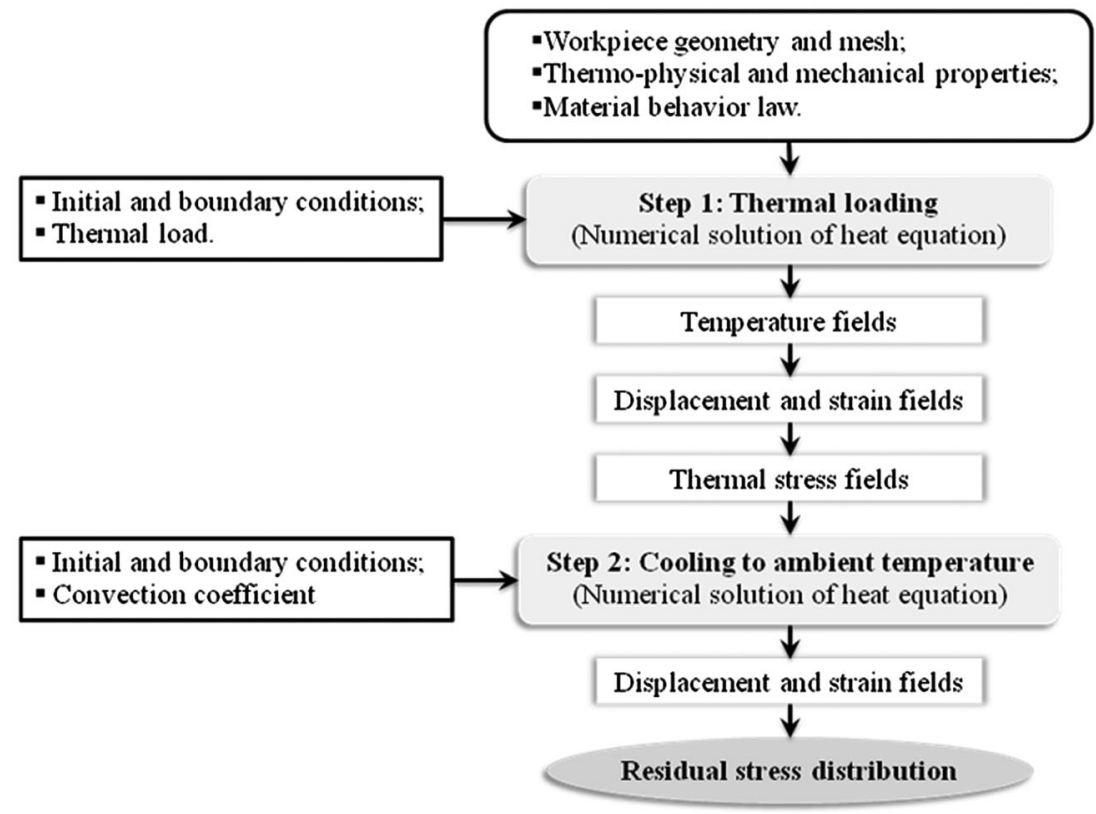

Fig. 7 Residual stress calculation procedure.

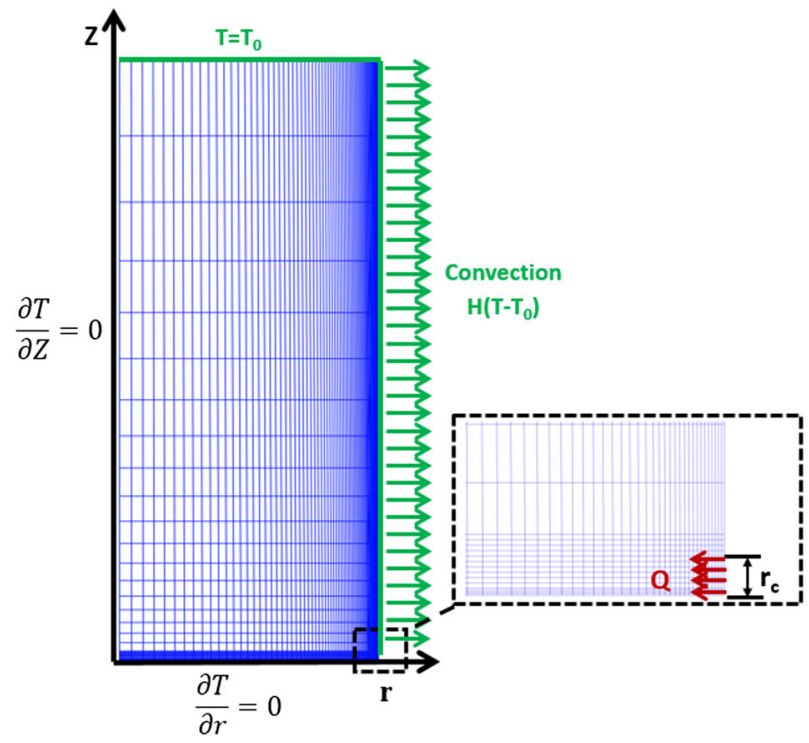

Fig. 8 Meshing and initial conditions used for the simulation.

results of three fatigue tests). This reduction becomes more important when the surface defect density is much higher.

Role of the surface topography and machining defects on the site distribution of fatigue cracks

The role of surface mode preparation on the characteristics of fatigue crack networks has been identified by SEM examinations of fatigue loaded specimen surface.
- Reference state (electropolished surface)

Fatigue crack nucleation has a crystallographic character. Indeed, the fatigue micro-cracks $(10 \mu \mathrm{m})$ occur at the persistent bands at the grain scale (Fig. 11a). The growth and coalescence of these micro-cracks lead to the formation of fatigue cracks at the scale of several grains, which propagate into the ductile bulk material and results on the workpiece fracture (Fig. 11b).

- Machined state

Fatigue crack nucleation is controlled by the machined surface topography. Indeed, long fatigue cracks $(200 \mu \mathrm{m})$ appear at the bottom of the cutting grooves (Fig. 11c and d). The rebuilt material contribute to the linking of the fatigue cracks and favors their coalescence from a groove to another, leading to the formation of long and deeper instable fatigue cracks that propagate rapidly and lead to the final fracture (Fig. 12a). This fatigue crack nucleation and growth mechanisms are accelerated by the material rebuilt density and inter-groove distance (Fig. 12b). This explains the results of the fatigue life evaluation corresponding to the different surface preparations.

\section{Role of the stabilized residual stress distribution}

Low-cycle fatigue loading relaxes, partially or totally, the machining residual stress in both directions (Fig. 13). The residual stress relaxation is more 

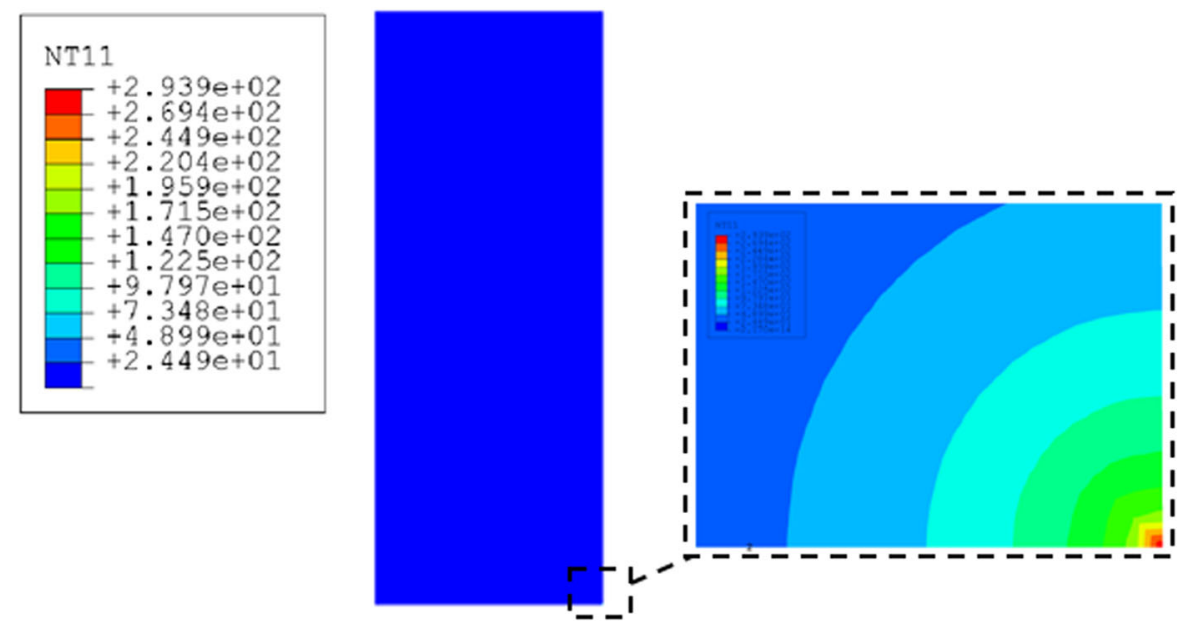

(a)
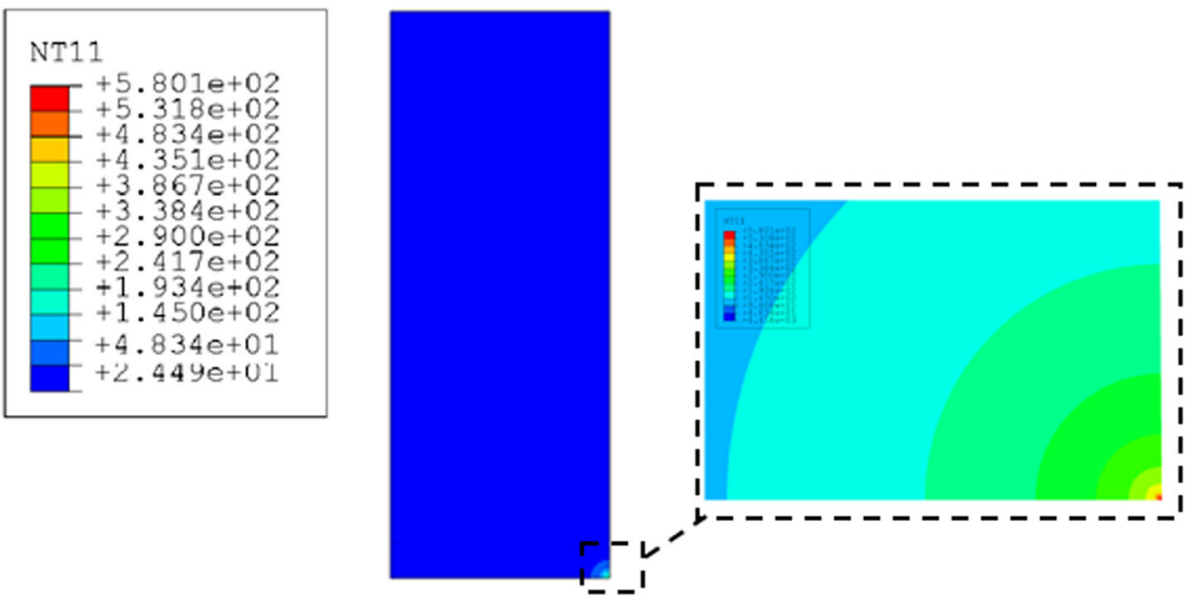

(b)

Fig. 9 Simulated nodal temperature distribution (in ${ }^{\circ} \mathrm{C}$ ) corresponding to Condition 1: (a) first model result (without rebuilt material) and (b) second model result (with rebuilt material).

important when the imposed strain amplitude is high (Table 6, columns E and F).

\section{DISCUSSION}

The experimental results established in this study confirm quantitatively the detrimental effect of the high surface roughness and machining defects on the fatigue life of machined parts. ${ }^{8}$ Indeed, the reduction of AISI 304 low-cycle fatigue life varies from $-22 \%$ to $-65 \%$ for the machined specimens with respect to electropolished one. This loss of fatigue resistance is attributed to the effect of machined surface quality on the fatigue crack source distribution and their cycling stability.

\section{Effect of surface quality on the fatigue crack nucleation}

Scanning electron microscope micrographs analysis supports the well-known ${ }^{9,19}$ role of the grooves as a stress concentration sites promoting crack nucleation as illustrated by the long cracks observed systematically in the bottom of the machining grooves (Fig. 11c and d). However, cracks seem to nucleate at the vicinity of the rebuilt material and dislodgements themselves are located in the bottom of grooves (Fig. 12b). Consequently, higher is the density of the machining defects; higher are the nucleation sites and lower is the fatigue life. Indeed, fatigue life degradation, with respect to the electropolished state, increases from $-22 \%$ to $-65 \%$ with increasing the defect density from 5 to 60 particles $/ \mathrm{mm}^{2}$. Moreover, the results reported in Table 6 show that the effect of rebuilt material and dislodgements outweighs the effect of stress 


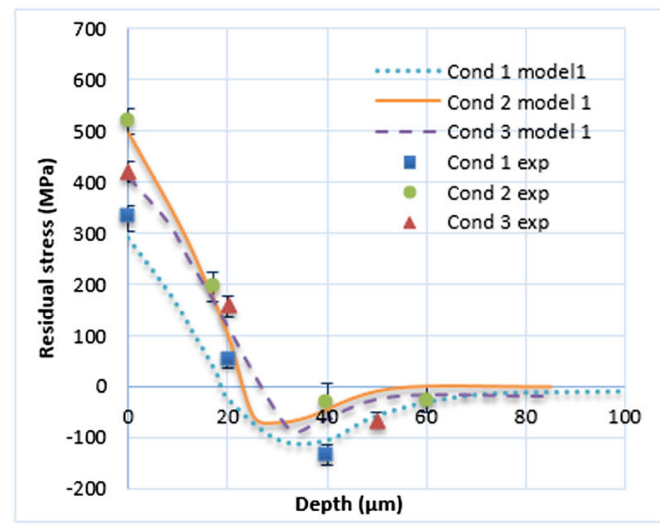

(a) Hoop stress

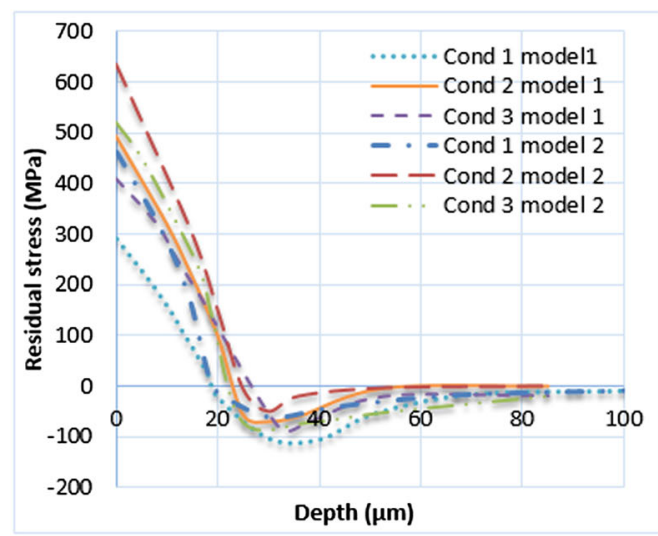

(c) Hoop stress

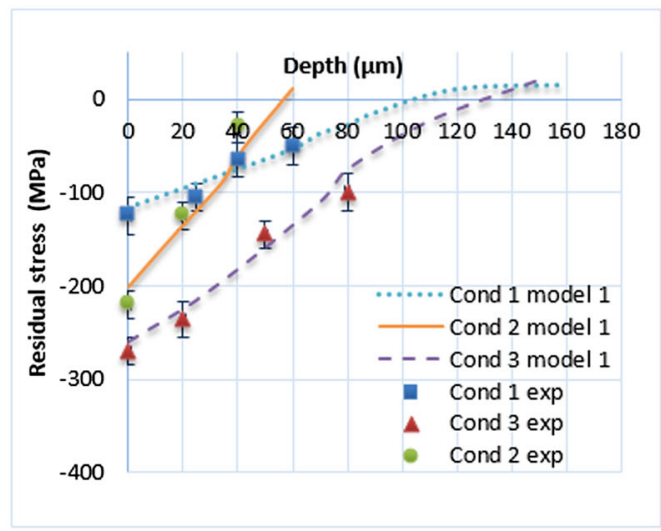

(b) Axial stress

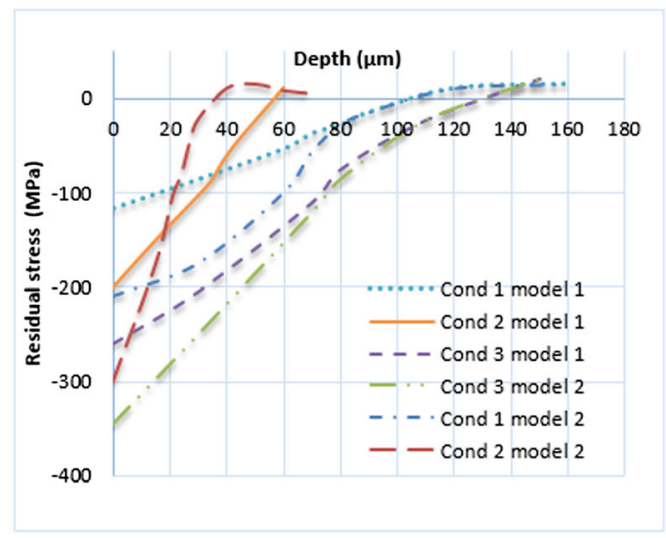

(d) Axial stress

Fig. 10 Residual stress distributions: (a) and (b) comparison between Model 1 (simulated results without considering the effect of the rebuilt material) and DRX measurements; (c) and (d) comparison between simulated results Models 1 and 2 (the effect of the rebuilt material is taken into account in calculation).

Table 6 Effect of surface preparation on the fatigue lifetime $\left(N_{R}\right)$

\begin{tabular}{|c|c|c|c|c|c|c|}
\hline A & & & $\mathrm{C}$ & $\mathrm{D}$ & $\mathrm{E}$ & $\mathrm{F}$ \\
\hline \multirow[b]{2}{*}{$\begin{array}{l}\text { Cutting } \\
\text { conditions }\end{array}$} & \multicolumn{2}{|c|}{ Fatigue life time } & \multirow[b]{2}{*}{$\begin{array}{c}\text { Rebuilt } \\
\text { material density } \\
\left(\text { particles } / \mathrm{mm}^{2} \text { ) }\right.\end{array}$} & \multirow[b]{2}{*}{$\begin{array}{c}\text { Stress } \\
\text { concentration } \\
\text { factor } K_{t}\end{array}$} & \multirow{2}{*}{$\begin{array}{l}\text { Hoop } \\
\text { residual } \\
\text { stress } \\
(\mathrm{MPa})\end{array}$} & \multirow{2}{*}{$\begin{array}{l}\text { Axial } \\
\text { residual } \\
\text { stress } \\
(\mathrm{MPa})\end{array}$} \\
\hline & $\begin{array}{c}\text { Imposed } \\
\text { strain } \frac{\Delta s t}{2}(\%)\end{array}$ & $\begin{array}{l}\text { Fatigue life } \\
\text { time } \\
N_{R} \text { (cycles) }\end{array}$ & & & & \\
\hline \multirow[t]{3}{*}{ Condition 1} & 0.3 & $27211 \pm 522$ & \multirow[t]{3}{*}{60} & \multirow[t]{3}{*}{1.06} & $230 \pm 15$ & $-320 \pm 18$ \\
\hline & 0.5 & $4620 \pm 40$ & & & $160 \pm 23$ & $-240 \pm 21$ \\
\hline & 1 & $590 \pm 40$ & & & $85 \pm 12$ & $-150 \pm 14$ \\
\hline \multirow[t]{3}{*}{ Condition 2} & 0.3 & $34745 \pm 780$ & \multirow[t]{3}{*}{25} & \multirow[t]{3}{*}{1.1} & $460 \pm 17$ & $-160 \pm 12$ \\
\hline & 0.5 & $6875 \pm 530$ & & & $290 \pm 14$ & $-116 \pm 25$ \\
\hline & 1 & $740 \pm 82$ & & & $150 \pm 22$ & $-40 \pm 09$ \\
\hline \multirow[t]{3}{*}{ Condition 3} & 0.3 & $60380 \pm 987$ & \multirow[t]{3}{*}{5} & \multirow[t]{3}{*}{1.13} & $310 \pm 14$ & $-182 \pm 17$ \\
\hline & 0.5 & $8540 \pm 754$ & & & $250 \pm 22$ & $-105 \pm 11$ \\
\hline & 1 & $938 \pm 83$ & & & $120 \pm 17$ & $-60 \pm 14$ \\
\hline \multirow{3}{*}{$\begin{array}{l}\text { Electropolished } \\
\text { state }\end{array}$} & 0.3 & $77290 \pm 1365$ & \multirow[t]{3}{*}{0} & \multirow[t]{3}{*}{1} & 0 & 0 \\
\hline & 0.5 & $10900 \pm 1142$ & & & 0 & 0 \\
\hline & 1 & $1120 \pm 167$ & & & 0 & 0 \\
\hline
\end{tabular}




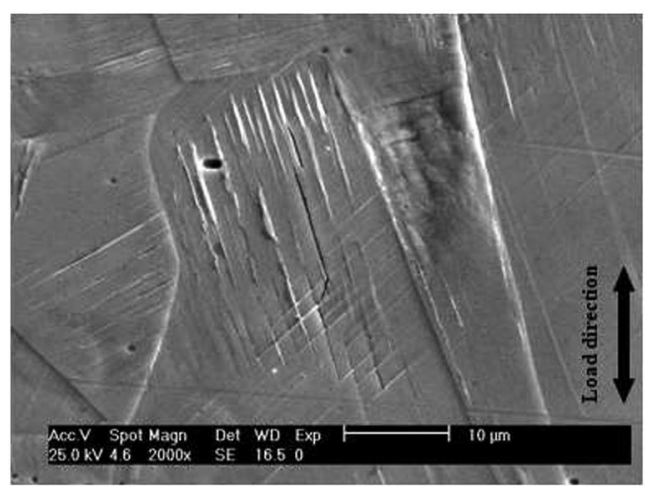

(a)

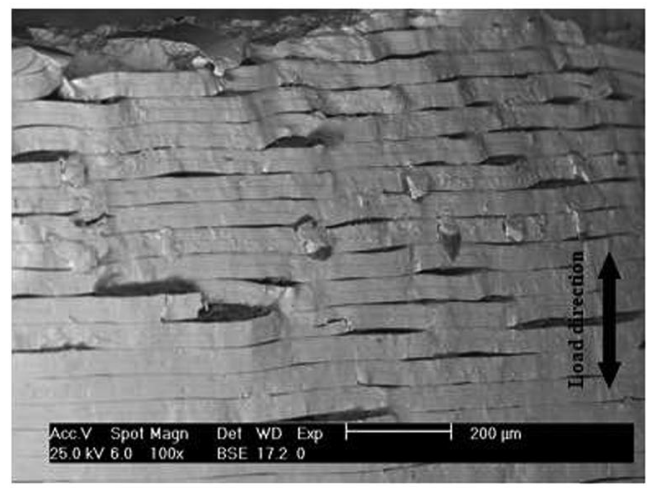

(c)

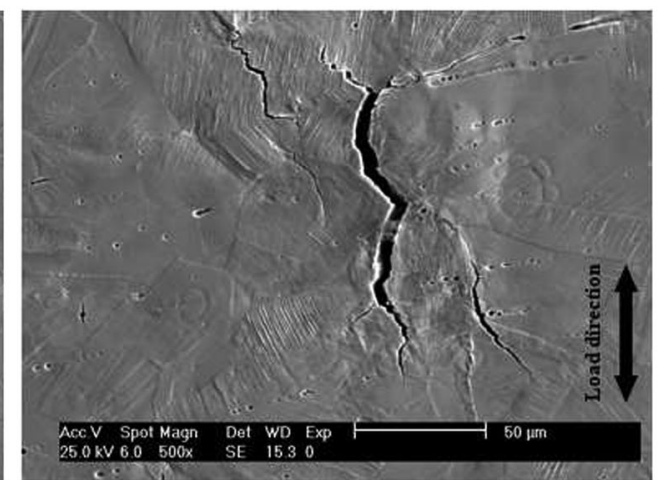

(b)

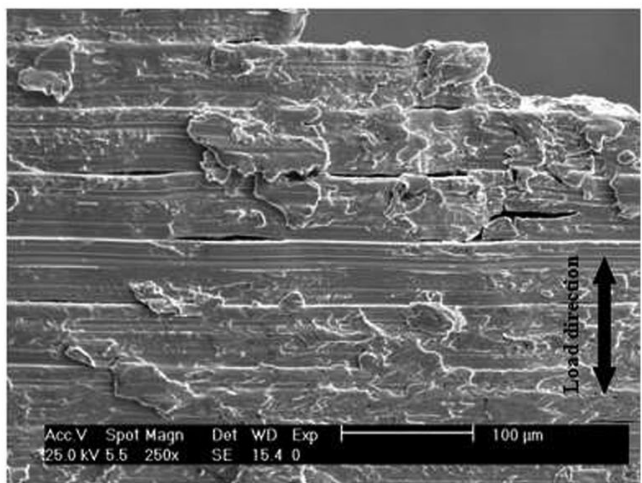

(d)

Fig. 11 Fatigue crack nucleation: (a) and (b) electropolished surface loaded at a strain amplitude value $\frac{\Delta \varepsilon t}{2}=0.5 \%$ and fractured at $\mathrm{N}_{\mathrm{R}}=9758$ cycles; (c) and (d) machined surface using Condition 1 loaded at a strain amplitude $\frac{\Delta s t}{2}=0.5 \%$, and fractured at $\mathrm{N}_{\mathrm{R}}=4580$ cycles.

concentration resulting from grooves. Indeed, the fatigue life at imposed strain amplitude decreases with an increase in defect density in spite of low stress concentration factor related to groove micro-geometrical characteristics. This result is in disagreement with the previous founding, which assumed a fatigue life decrease with increasing $K_{t .}{ }^{19}$ Therefore, the controversial result can be resolved by considering the contribution of the additional increase of the tensile residual stresses, induced by the rebuilt material, to promote the fatigue crack nucleation. In fact, the numerical simulation procedure developed in this study confirms the increase of local tensile residual stress related to the rebuilt material which acts as a second heat source and contribute to the friction increase at tool-workpiece interface as supported by Selvam et al. ${ }^{5}$ Similar results were obtained by Arunachalam et $\mathrm{al}^{7}$ where high values of tensile residual stresses are measured when Inconel 718 was machined. They attribute these values to the high temperatures and localized thermal effect induced by the residual built-up edge adhered to the machined surface. The consequence of the rebuilt material on the AISI 304 fatigue crack nucleation life is illustrated by the results given in Table 6. It shows a fatigue lifetime decreasing with an increase in the rebuilt material density. This result is in accordance to the well-known detrimental effect of tensile residual stress on the fatigue crack nucleation, which considered as damaging stress. ${ }^{20}$

\section{Effect of surface quality on the fatigue crack growth}

The SEM examinations illustrate the role of the network cracks nucleated at the vicinity of the rebuilt material in fatigue crack coalescence. Fig. 12a shows that the branched cracks related to the rebuilt material favor the coalescence of cracks from a groove to another promoting therefore rapid crack growth that lead to premature fracture. Higher is the rebuilt material density, rapid is the fatigue crack coalescence and lower fatigue life is. This phenomenon is strongly associated with the high tensile residual stress field as supported by Makhlouf et $a l^{20}$ observations for the AISI 304. Indeed, the machining-induced tensile residual stress exhibits a detrimental effect by promoting early appearance of long crack lengths and rapid propagation $\left(d a / d N=C\left(\Delta K_{\text {eff }}\right)^{n}\right)$ resulting from high effective stress intensity $\left(K_{\text {eff }}\right)$, which is the sum $\left(K_{\text {eff }}=K_{S}+K_{\mathrm{RES}}\right)$ of the stress intensity due to external loading $\left(K_{S}\right)$, and the stress intensity due to the tensile residual stress $\left(K_{\mathrm{RES}}\right)$. On the other hand, the surface embrittlement, induced by the work-hardening, 


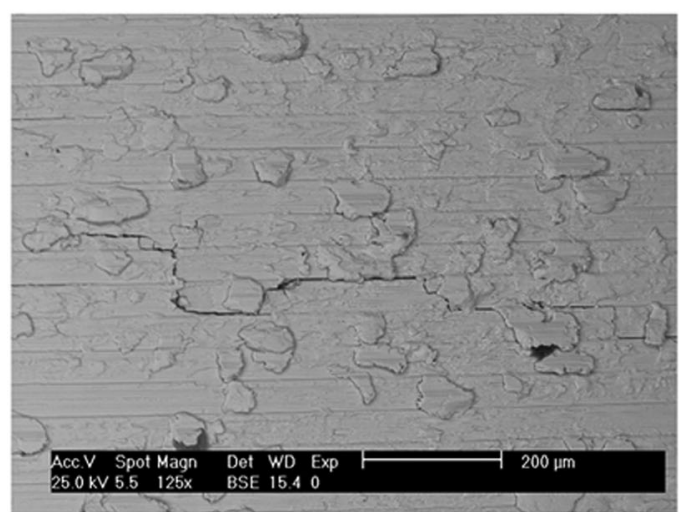

(a)

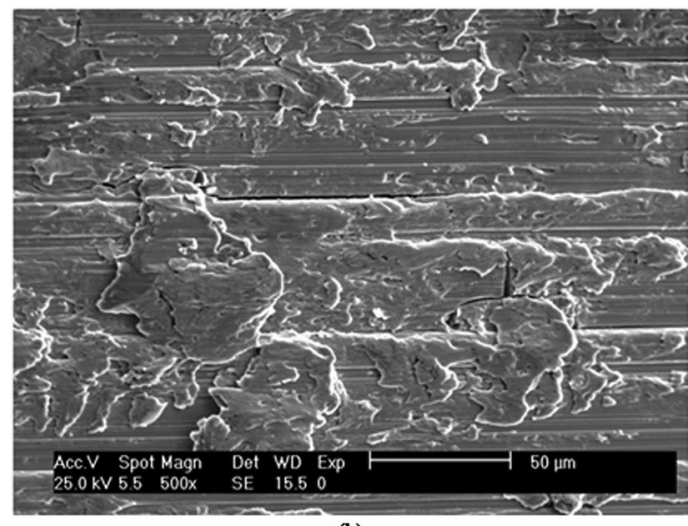

(b)

Fig. 12 Fatigue crack croissance and coalescence (Condition 1): (a) loaded at a strain amplitude value $\frac{\Delta \varepsilon t}{2}=0.5 \%$ and fractured at $\mathrm{N}_{\mathrm{R}}=4580$ cycles and (b) loaded at a strain amplitude value $\frac{\Delta \varepsilon t}{2}=1 \%$ and fractured at $\mathrm{N}_{\mathrm{R}}=550$ cycles.

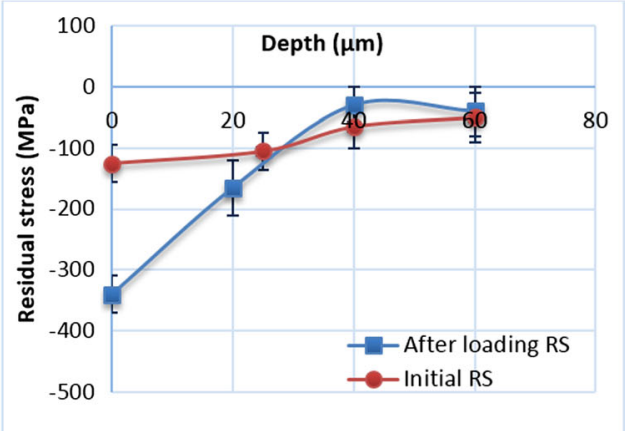

(a)

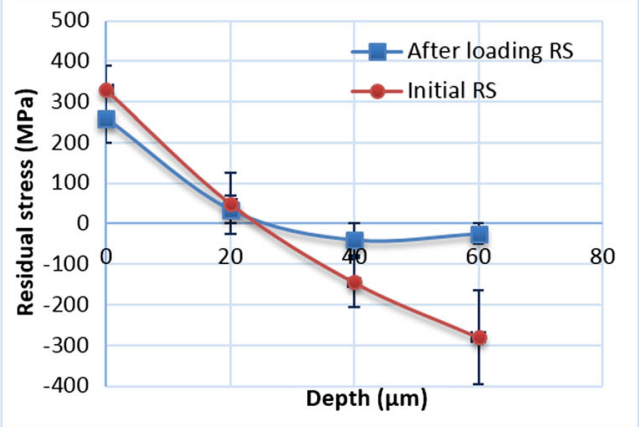

(b)

Fig. 13 Stabilized residual stress profiles determined by X-ray diffraction, Condition $1\left(\frac{\Delta \varepsilon t}{2}=0.3 \%, \mathrm{~N}_{\mathrm{R}}=26689\right)$, (a) axial stress and (b) hoop stress.

accelerates the first stage of fatigue crack propagation. This result is in agreement with those obtained by Sidhom et al..$^{21}$ on the AISI 316 stainless steel.

\section{CONCLUSIONS}

In this study, the effect of machining defects and residual stress on the stainless steel fatigue life has been investigated by experimental and numerical approaches. The main results can be summarized as follows:

- Machining defect as rebuilt material and dislodgements were often induced by cutting of difficult to machining AISI 304 stainless steel. The rebuilt material density increases with a decrease in the cutting speed.

- The rebuilt materials generate an additional tensile residual stress and work-hardening which contribute to fatigue cracks nucleation at the vicinity of these particles. The coalescence of nucleated cracks under cyclic loading is responsible of the fatigue life reduction ranging from $-22 \%$ to $-65 \%$ with respect to the electropolished parts free from defects.
- The additional tensile residual stress and workhardening, induced by the rebuilt material, accelerate the fatigue crack nucleation and growth.

\section{REFERENCES}

1 Ben Moussa, N., Sidhom, H., and Braham, C. (2014) Numerical and experimental analysis of residual stress and plastic strain distributions in machined stainless steel. Int. F. Mech. Sci., 64, 82-93.

2 Ciftci, I. (2006) Machining of austenitic stainless steels using CVD multi-layer coated cemented carbide tools. Tribol. Int., 39: 565-569.

3 Tekıner, Z., and Yesılyurt, S. (2004) Investigation of the cutting parameters depending on process sound during turning of AISI 304 austenitic stainless steel. Mater. Des., 25, 507-513.

4 Xavior, M. A., and Adithan, M. (2009) Determining the influence of cutting fluids on tool wear and surface roughness during turning of AISI 304 austenitic stainless steel. 7. Mater. Process. Technol., 209, 900-909.

5 Selvam, M. S., and Radhakrishnan, V. (1973) Characteristics of a surface machined with a single point tool. Tribology, 6, 93-96.

6 Bakkal, M., Shih, A. J., and Scattergood, R. O. (2004) Chip formation, cutting forces, and tool wear in turning of $\mathrm{Zr}$-based bulk metallic glass. Int. 7. Mach. Tools Manuf, 44, 915-925. 
7 Arunachalam, R. M., Mannan, M. A., Spowage, M. A. (2004) Surface integrity when machining age hardened Inconel 718 with coated carbide cutting tools. Int. 7. Mach. Tools Manuf, 44, 1481-1491.

8 Novovic, D., Dewes, R. C., Aspinwall, D. K., Voice, W., and Bowen, P. (2004) The effect of machined topography and integrity on fatigue life. Int. F. Mach. Tools Manuf, 44, 125-134.

9 Lee, J. M., and Nam, S. W. (1990) Effect of crack initiation mode on low cycle fatigue life of type 304 stainless steel with surface roughness. Mater. Lett., 10(6), 223-230.

10 www.sandvik.com

11 Moufki, A., Devillez, A., Dudzinski, D., and Molinari, A. (2004) Thermomechanical modelling of oblique cutting and experimental validation. Int. 7. Mach. Tools Manuf, 44, 971-989.

12 Mamalis, A. G., Branis, A. S., and Manolakos, D. E. (2002) Modeling of precision hard cutting using implicit finite element methods. F. Mater. Process. Technol., 123, 464-475.

13 Tache, C., Tudor, A., and Tache, A. (2003), The analysis of the temperature state generated by friction during the cutting processes. The annals of university "dunărea de jos" of galati fascicle viii, tribology. 1221-4590.

14 Abukhshim, N. A., Mativenga, P. T., and Sheikh, M. A. (2005) Investigation of heat partition in high speed turning of high strength alloy steel. Int. F. Mach. Tools Manuf, 45, 1687-1695.
15 Salio, M., Berruti, T., and De Poli, G. (2006) Prediction of residual stress distribution after turning in turbine disks. Int. $\mathcal{F}$. Mech. Sci., 48, 976-984.

16 Yang, X., and Liu, C. R. (2002) A new stress-based model of friction behavior in machining and its significant impact on residual stresses computed by finite element method. Int. F. Mech. Sci., 44, 703-723.

17 Johnson, G. R., and Cook, W. H. (1983) A constitutive model and data for metals subjected to large strains, high strain rate, and temperatures. Proceedings of the seventh international symposium on Ballistics, The Hague, The Netherlands. 54, 541-547.

18 Moulik, P. N., Yang, H. T. Y., and Chandrasekar, S. (2001) Simulation of thermal stresses due to grinding. Int. F. Mech. Sci., 43, 831-851.

19 Suraratchai, M., Limido, J., Mabru, C., and Chieragatti, R. (2008) Modelling the influence of machined surface roughness on the fatigue life of aluminium alloy. Int. F. Fatigue, 30, 2119-2126.

20 Makhlouf, K., Sidhom, N., Khlifi, A., Sidhom, H., and Braham, C. (2013) Low cycle fatigue life improvement of AISI 304 by initial and intermittent wire brush hammering. Mater. Des., 52, 1088-1098.

21 Sidhom, N., Makhlouf, K., Khlifi, A., Braham, C., and Sidhom, H. (2014) Assessment of low cycle fatigue improvement of machined AISI 316 stainless steel by brush hammering. Fatigue Fract. Eng. Mater. Struct. DOI: 10.1111/ffe.12179. 